(Article)

\title{
Regeneration of Pinus halepensis (Mill) through organogenesis from apical shoot buds
}

\author{
Cátia Pereira ${ }^{1,2}$, Itziar A. Montalbán ${ }^{2}$, Ana Pedrosa ${ }^{1}$, Jéssica Tavares ${ }^{1}$, Alexey Pestryakov ${ }^{3}$, \\ Nina Bogdanchikova ${ }^{4}$, Jorge Canhoto ${ }^{{ }^{*}}$, Paloma Moncaleán ${ }^{2 *}$ \\ 1 Center for Functional Ecology, Department of Life Sciences, University of Coimbra, Coimbra, Portugal; \\ catia.pereira@student.uc.pt (C.P.); anasimoespedrosa@gmail.com (A.P.1); jessicatavares96@gmail.com (J.T.); \\ jorgecan@uc.pt (J.C.) \\ 2 Department of Forestry Science, NEIKER, Arkaute, Spain; imontalban@neiker.eus (I.A.M.); \\ pmoncalean@neiker.eus (P.M.) \\ 3 Department of Technology of Organic Substances and Polymer Materials, Tomsk Polytechnic University, \\ Tomsk, Russia; pestryakov@tpu.ru (A.P.²) \\ 4 Center for Nanosciences and Nanotechnology, National Autonomous University of Mexico, Ensenada, \\ México; nina@cnyn.unam.mx (N.B.); \\ * Correspondence: jorgecan@uc.pt (J.C.); pmoncalean@neiker.eus (P.M.)
}

\begin{abstract}
Organogenesis and somatic embryogenesis have been widely applied as the two main regeneration pathways in plant tissue culture. However, recalcitrance is still a main restriction in the clonal propagation of many woody species, especially in conifers. They undergo a "phase change" that leads to significant loss of organogenic and embryogenic capacity, thus reducing the responsive tissues or organs to juvenile material, and narrowing the competence window. In this sense, in vitro regeneration of mature conifer trees has been a long-cherished goal in many laboratories worldwide. In this work, apical shoot buds were used as explants for both organogenesis and somatic embryogenesis in order to cloning mature trees of Aleppo pine. Reinvigorated axillary shoots were submitted to somatic embryogenesis induction through the manipulation of culture media, including the use of auxins such as 2,4-D and NAA, cytokinins (BA and kinetin) and phytosulfokine (50, 100 and $200 \mathrm{nM}$ ). Although somatic embryos could not be obtained, embryogenic-like tissue was produced followed by the appearance of actively proliferating non-embryogenic calli and differences between treatments were found, especially when phytosulfokine was added to the induction media. Organogenic system produced reinvigorated shoots from both BA treatments tested (22 and $44 \mu \mathrm{M})$, from juvenile somatic trees and adult trees, and ex-vitro acclimatized plants were developed.
\end{abstract}

Keywords: Aleppo pine; conifers; phytosulfokine; plant growth regulators; somatic embryogenesis

\section{Introduction}

Approximately $52 \%$ of land surface is occupied by forests and among them [1] conifers are particularly important, since they are by far the largest and most diverse gymnosperm group, covering approximately $60 \%$ of the forested areas of the world [2]. In vitro propagation techniques have been widely applied both as a model system for plant regeneration analysis as well as a largescale propagation system for coniferous cloning [2,3]. Aleppo Pine (Pinus halepensis Mill.) is a native pine of the Mediterranean region that prevails in the driest and warmest sites due to its tolerance to high temperatures and drought stress $[4,5]$ which makes it a potential alternative for reforestation in the climate change scenario predicted for large areas of the globe in the near future [6,7].

The individual body of a multicellular organism contains multiple types of tissues, each consisting of cells with particular features and functions. However, in some cases, these attributes 
can be totally or partially lost and the cells return to a more juvenile state by a process called dedifferentiation [8]. Cellular plasticity defines the competence of differentiated cells to switch their differentiation process and to acquire new fates. This loss of a specialized state previously acquired during development has been one of the central concepts in plant regeneration [9].

In vitro regeneration of plants can be accomplished through two different pathways, namely shoot organogenesis and somatic embryogenesis (SE) [10,11]. Organogenesis relies on de novo formation of a shoot that requires further rooting to obtain an entire plant. On the other hand, SE makes possible the regeneration of an entire plant through the formation of somatic embryos. However, SE is mostly constrained to juvenile embryonary organs and, in most cases, immature zygotic embryos have been used to achieve somatic embryogenesis induction in coniferous and other tree species [12]. Obviously, regeneration from embryonary explants precludes the selection of specific traits that can only be seen when trees have already entered their mature phase, but, the switch of the developmental program of adult cells is still difficult in many plant species, especially in forest trees [13]. Recalcitrance is a main restriction in the clonal propagation of many woody species, such as conifers, and clonal propagation of many of these species is still problematic, particularly in attempts to clone adult trees [12,14].

The direct induction of axillary shoot buds and somatic embryos formation are morphogenic processes that are highly influenced by exogenous plant growth regulators and their interaction with endogenous phytohormones in the explants [15]. The balance between auxin and cytokinin, and changes on their composition and ratio on culture media, has been found to determine the morphogenic competence of an in vitro explant [16]. Variations of this ratio is frequently the primary empirical approach to the optimization of in vitro culture; however, many species do not respond to this classical approach and require additional optimization by the variation of other chemical or physical factors of culture media [10]. Endogenous and environmental factors such as genotype, tissue and timing of excision, phenology and tree maturation are also limiting aspects for regeneration in these species [12].

Protocols for organogenesis of adult pines has been achieved in our lab [17-20] and SE have been successfully reported in various Pinus species using juvenile material as initial explant [21-23]. Cloning of adult conifers by SE is still a cherished goal since in this case superior individuals for many identified traits could be selected for propagation. Also, the period of field testing of clones, as it is done when SE is obtained from zygotic embryos, would not be needed and considerable time would be gained [14]. Therefore, cloning of adult trees is still being attempted in numerous laboratories.

In Aleppo pine, the first record of organogenesis was reported using mature zygotic embryos as explants [24]. More recently, our team successfully developed the first SE protocol using immature megagametophytes as explants for this species [25].

Taking into account the above-mentioned reasons, the main goal of this work was to successfully develop protocols for organogenesis and SE, using apical shoot buds as explants, which could allow the selection and cloning of mature trees of Aleppo pine.

\section{Materials and Methods}

\subsection{Induction of organogenesis}

\subsubsection{Plant material}

Apical shoot buds (0.5-3 cm length) (Figure 1a, b) were collected from January to March (2017). Four adult zygotic trees (17.3, 17.4, 17.5 and 18.1) from Manzanos (Spain; 42 $44^{\prime} 29^{\prime \prime} \mathrm{N}, 2^{\circ} 52^{\prime} 35^{\prime \prime} \mathrm{W}$ ) and four juvenile somatic trees (H8, H29, H32 and H5) planted at Neiker, Arkaute (Spain; 42 $51^{\prime} 08.5^{\prime \prime}$ N, 2 ${ }^{\circ} 37^{\prime} 37.1^{\prime \prime} \mathrm{W}$ ) were selected. In 2018, five adult trees (P1, P5, P6, P7 and P8) were collected from November to January near Aveiro (Portugal; $40^{\circ} 09^{\prime} 02.5^{\prime \prime} \mathrm{N}, 8^{\circ} 49^{\prime} 07.3^{\prime \prime} \mathrm{W}$ ).

Apical shoot buds were stored in polyethylene bags at $4{ }^{\circ} \mathrm{C}$ for a maximum of 10 days until their use. For cleansing, buds were washed with commercial detergent, rinsed under running water for 5 min and then immersed in ethanol $96 \%$ for $1 \mathrm{~min}$. Afterwards, in the first sample collection (2017), explants were initially submitted to three different sterilization protocols: (A) surface sterilization in 
commercial bleach 1: 1 diluted with sterile water plus two drops of Tween $20^{\circledR}$ for 15-20 min and then rinsed three times under sterile distilled $\mathrm{H}_{2} \mathrm{O}$; (B) surface sterilization in commercial bleach 1: 1 diluted with sterile water plus two drops of Tween $20^{\circledR}$ for $15 \mathrm{~min}$, rinsed one time with sterile distilled $\mathrm{H}_{2} \mathrm{O}$, immersed in silver nanoparticles solution (Argovit ${ }^{\circledR}$, Vector Vita LLC, Novosibirsk, Russia) (200 $\mathrm{mg} \mathrm{L}^{-1}$ ) for $10 \mathrm{~min}$ and then rinsed three times under sterile distilled $\mathrm{H}_{2} \mathrm{O}$; (C) surface sterilization in silver nanoparticles solution (Argovit ${ }^{\circledR}$, Vector Vita LLC, Novosibirsk, Russia) (200 $\mathrm{mg} \mathrm{L}^{-1}$ ) for $15 \mathrm{~min}$ and then rinsed three times under sterile distilled $\mathrm{H}_{2} \mathrm{O}$. All sterilization protocols were performed under sterile conditions in the laminar flow unit. In the second collection in 2017 and thereafter in 2018, the sterilization protocol (A), was used for all the explants. Lastly, the bud scales were removed (Figure 1c), and buds were cut transversely with a surgical scalpel blade into $0.3-0.8$ $\mathrm{cm}$ thick slices.

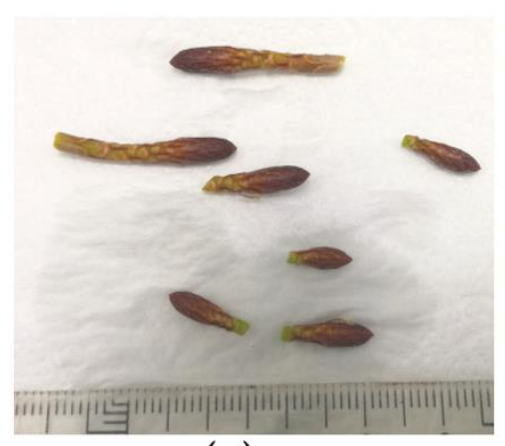

(a)

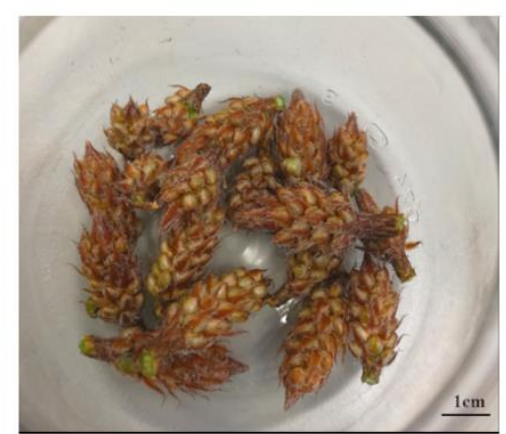

(b)

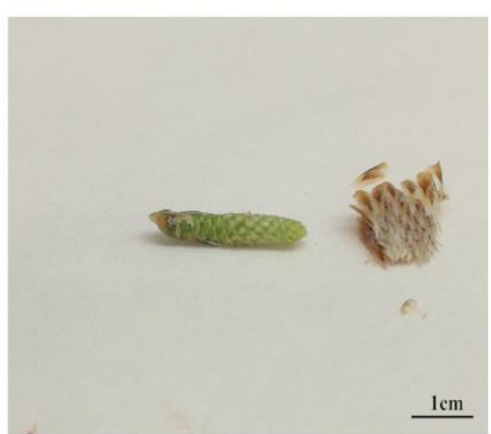

(c)

Figure 1. Apical shoot buds preparation for culture: (a) Apical shoot buds with different sizes, with totally closed scales; (b) Apical shoot buds at an advanced developmental stage with open scales; (c) Apical shoot with bud scales removed.

\subsubsection{Axillary shoot induction}

Buds slices were cultured in DCR medium [26] supplemented with $30 \mathrm{~g} \mathrm{~L}^{-1}$ sucrose and $9 \mathrm{~g} \mathrm{~L}^{-1}$ Difco $^{\circledR}$ granulated agar (Becton Dickinson, Franklin Lakes, USA) (Figure 2a). Two different concentrations of 6-benzyladenine (BA, 11 and $22 \mu \mathrm{M}$ ), were tested in the first sample collection of 2017. The $\mathrm{pH}$ was adjusted to 5.8 before autoclaving at $121{ }^{\circ} \mathrm{C}$ for $20 \mathrm{~min}$. Twenty milliliters of medium were poured into each $90 \times 14 \mathrm{~mm}$ Petri dish. In each sample collection, four to five bud slices were placed on each Petri dish. Five to six Petri dishes per BA treatment and genotype were cultured. The explants were maintained at $23{ }^{\circ} \mathrm{C}$ under a $16 \mathrm{~h}$ photoperiod at $100 \mu \mathrm{mol} \mathrm{m} \mathrm{m}^{-2} \mathrm{~s}^{-1}$ provided by cool white fluorescent tubes (TFL 58 W/33; Philips, France).

After 35-50 days in culture (when elongating needles fascicles were evident), the explants were placed on elongation medium. The elongation medium was the same as the previous one but without plant growth regulators and supplemented with $2 \mathrm{~g} \mathrm{~L}^{-1}$ activated charcoal, $30 \mathrm{~g} \mathrm{~L}^{-1}$ sucrose and $9.5 \mathrm{~g}$ $\mathrm{L}^{-1} \mathrm{Difco}^{\circledR}$ granulated agar (Becton Dickinson, Franklin Lakes, USA). The $\mathrm{pH}$ of the medium was adjusted to 5.8 .

After 35 days from the first collection date in 2017, the elongated needles were cut off and the explants were transferred to the same medium with cytokinins to promote axillary bud growth in a re-induction period. At this point, since the explants cultured at the concentration of $11 \mu \mathrm{M}$ of BA did not presented the expected response they were transferred to induction medium with $44 \mu \mathrm{M}$ of BA. At the second and third collection in 2017 and all three collections in 2018, the initial BA concentrations tested were then 22 and $44 \mu \mathrm{M}$ of BA. When the needle fascicles emerged, the explants with axillary buds were cultured in glass jars with elongation medium (Figure $2 b$ ). 


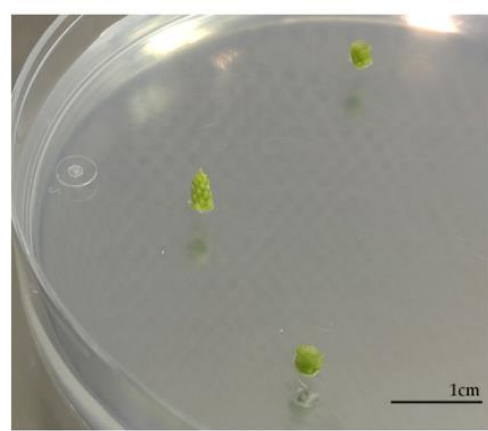

(a)

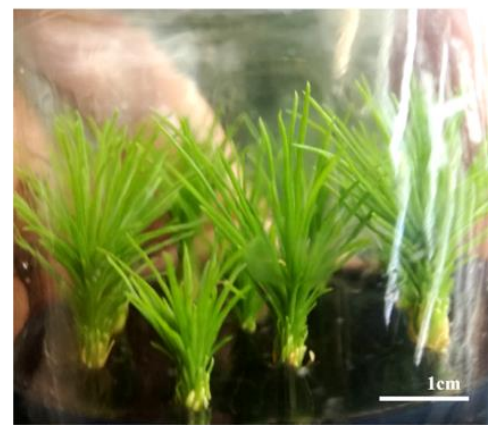

(d)

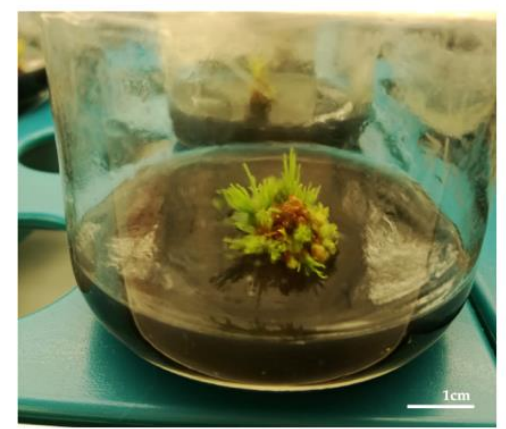

(b)

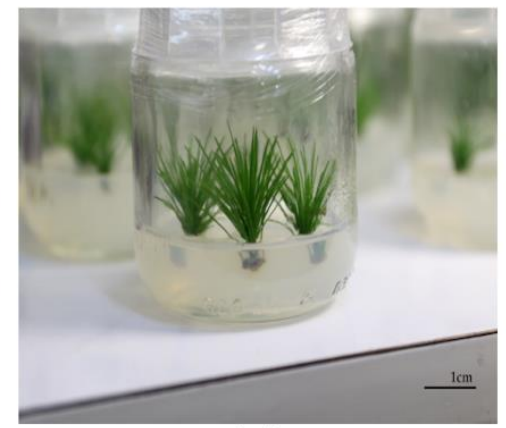

(e)

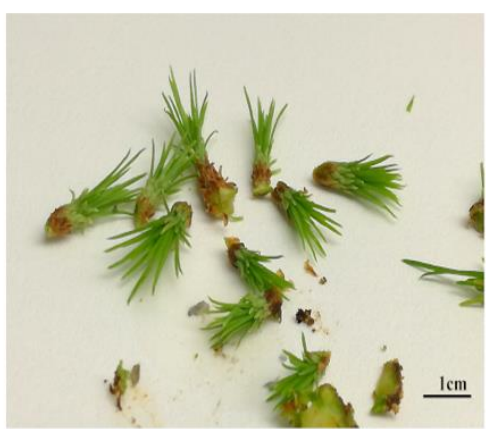

(c)

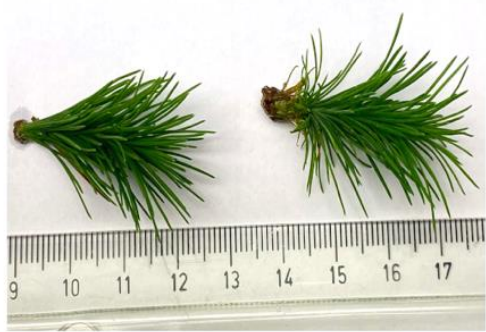

(f)

Figure 2. Plant material at different stages of the organogenic process: (a) Bud slices in induction medium; (b) Shoot organogenesis in a bud slice cultured at elongation medium; (c) Separation of axillary shoots from initial explant; (d) Axillary shoots separately cultured on elongation medium; (e) Shoots in root-induction medium; (f) Shoots with no roots immediately before acclimatization.

\subsubsection{Axillary shoot growth and elongation}

When axillary bud growth was evident, explants were transferred to elongation medium. Once shoots were $0.5 \mathrm{~cm}$ long, they were separated and cultured individually in fresh elongation medium (Figure 2c, d). The part of the explant that had secondary needles was separated, the secondary needles were cut, and explants were put again in induction medium to promote re-induction.

\subsubsection{Root-induction}

Shoots that were $2.0-3.0 \mathrm{~cm}$ long were transferred to the root-induction medium (Figure 2e, f). The medium was the same as used for axillary bud induction but without cytokinin and supplemented with $30 \mathrm{~g} \mathrm{~L}^{-1}$ sucrose and $7 \mu \mathrm{M}$ Indole-3-butyric acid (IBA). Three to four explants per five replicates of 5 genotypes (H8, H32, 17.3, P1 and P8) were submitted to root-induction medium. After 4 weeks of culture, shoots were transferred onto fresh elongation medium to promote root growth. None of the shoots developed visible roots so they were retransferred to root-induction medium for 2 weeks. After this time, no roots were developed in vitro (Figure 2f), so shoots were transferred ex vitro to sterile peat:perlite $(3: 1, \mathrm{v} / \mathrm{v})$ and acclimatized under controlled conditions. Four months later, acclimatization percentages were recorded.

\subsubsection{Data Collection and Statistical Analysis}

At the time that axillary shoots were isolated and cultured individually in elongation medium, the percentage of explants forming shoots [EFS (\%)] and the mean number of shoots formed per explant (NS/E) were calculated with respect to the non-contaminated explants. Following the confirmation of the homogeneity of variances and normality of the samples, an unpaired $t$-test analysis [GraphPad Prism 8.4.1 (676)] was performed in order to identify possible differences in these two variables regarding explants induction at 22 and $44 \mu \mathrm{M}$ of BA. Each measure was made by taking into account the mean data collected for each genotype at different sample collections (sample collections with 100 $\%$ contamination were not taken into account), comprising a total of 20 replicates per BA treatment. 
Regarding possible differences in acclimatization percentages between genotypes, since there was no homogeneity of variances between samples, a Kruskal-Wallis test was applied [GraphPad Prism 8.4.1 (676)] using the percentage of successfully acclimatized plants counted after 4 months.

\subsection{Towards somatic embryogenesis induction}

\subsubsection{Apical shoot buds}

A total of eight trees were selected in 2017. Six juvenile somatic trees (H29, H32, H13, H18, H5 and H42) planted at Neiker, Arkaute (Spain; 42 ${ }^{\circ} 51^{\prime} 08.5^{\prime \prime} \mathrm{N}, 2^{\circ} 37^{\prime} 37.1^{\prime \prime} \mathrm{W}$ ) and two adult zygotic trees (17.3 and 17.4) from Manzanos (Spain; 42 $44^{\prime} 29^{\prime \prime} \mathrm{N}, 2^{\circ} 52^{\prime} 35^{\prime \prime} \mathrm{W}$ ) were selected. Apical shoot buds (0.5$2.0 \mathrm{~cm}$ long) were collected from January to March, and stored in polyethylene bags at $4{ }^{\circ} \mathrm{C}$ for a maximum of 7 days until their use. For cleansing, buds were washed with commercial detergent, rinsed under running water for $5 \mathrm{~min}$ and immersed in ethanol $96 \%$ for $1 \mathrm{~min}$. The sterilization protocol was the same as described in section 2.1.1. After the sterilization, the bud scales were removed and buds were cut transversely with a surgical scalpel blade into $0.2-0.5 \mathrm{~cm}$ thick slices.

\subsubsection{Induction of bud explants}

Buds slices (Figure 2a) were first cultured in DCR medium supplemented with $32 \mathrm{~g} \mathrm{~L}^{-1}$ maltose, $3 \mathrm{~g} \mathrm{~L}^{-1}$ activated charcoal and $2 \mathrm{~g} \mathrm{~L}^{-1}$ gellan gum (Gelrite ${ }^{\circledR}$; Duchefa Biochemie, Amsterdam, Netherlands) [27]. The $\mathrm{pH}$ was adjusted to 5.7 before autoclaving at $121^{\circ} \mathrm{C}$ for $20 \mathrm{~min}$ and cultures were maintained for 3 days, at dark, at $4{ }^{\circ} \mathrm{C}$.

Afterwards, explants were cultured in induction medium which consisted in DCR medium supplemented with $32 \mathrm{~g} \mathrm{~L}^{-1}$ maltose, $9 \mu \mathrm{M}$ of BA, $20 \mu \mathrm{M}$ of 2,4-Dichlorophenoxyacetic acid (2,4-D) and $1.5 \mathrm{~g} \mathrm{~L}^{-1}$ gellan gum (Gelrite ${ }^{\circledR}$; Duchefa Biochemie, Amsterdam, Netherlands). The $\mathrm{pH}$ was adjusted to 5.7 before autoclaving at $121^{\circ} \mathrm{C}$ for $20 \mathrm{~min}$. After autoclaving, a filter-sterilized solution containing EDM amino acid mixture [28], $50 \mathrm{nM}$ of phytosulfokine and $25 \mu \mathrm{M}$ of 1-Naphthaleneacetic acid (NAA) were added to the cooled medium. Cultures were maintained, at dark, at $23^{\circ} \mathrm{C}$. Two to five Petri dishes per genotype and five bud slices per Petri dish were cultured.

\subsubsection{Proliferation}

After 3-5 weeks on induction medium, half of the embryogenic like proliferating calli were directly transferred to proliferation medium and half were detached from the bud slices. The detachment was made by resuspending the explants in growth regulators-free liquid DCR medium supplemented with $30 \mathrm{~g} \mathrm{~L}^{-1}$ sucrose, in $50 \mathrm{~mL}$ centrifuge tubes, and vigorously shaking them by hand for a few seconds. Thereafter, a $5 \mathrm{~mL}$ aliquot was poured onto a filter paper disc (Whatman no. 2, 7 $\mathrm{cm}$ ) in a Büchner funnel and a vacuum pulse was applied for $10 \mathrm{~s}$ [29]. Filters containing the tissue were then poured in proliferation medium that had the same composition to that used in the induction stage but a higher gellan gum concentration $\left(2.5 \mathrm{~g} \mathrm{~L}^{-1}\right)$ and two different concentrations, 50 and $100 \mathrm{nM}$, of phytosulfokine. Cultures were subcultured every 3-5 weeks and cultured in the dark, half at 23 and the other half at $28^{\circ} \mathrm{C}$. Embryogenic like tissue that presented a similar morphology to embryogenic callus, was selected and stained with $2 \%(\mathrm{w} / \mathrm{v})$ acetocarmine observed with a Leica DMS1000 (Leica Microsystems, Wetzlar, German).

\subsubsection{First approach to maturation induction}

After 2-3 subcultures on proliferation medium, all samples were resuspended, using the resuspension method described in 2.2.1.2., in growth regulators-free liquid DCR medium supplemented with $60 \mathrm{~g} \mathrm{~L}^{-1}$ sucrose and $10 \mathrm{~g} \mathrm{~L}^{-1}$ activated charcoal before being transferred to a prematuration medium. This prematuration medium was DCR medium supplemented with $32 \mathrm{~g} \mathrm{~L}^{-1}$ maltose, $9 \mu \mathrm{M}$ of BA, $20 \mu \mathrm{M}$ of 2,4-D, $200 \mathrm{mg} \mathrm{L}^{-1}$ of Polyvinylpyrrolidone (PVP) and $2.5 \mathrm{~g} \mathrm{~L}^{-1}$ gellan gum (Gelrite ${ }^{\circledR}$; Duchefa Biochemie, Amsterdam, Netherlands). The $\mathrm{pH}$ was adjusted to 5.7 before autoclaving at $121^{\circ} \mathrm{C}$ for $20 \mathrm{~min}$. After autoclaving, a filter-sterilized solution containing EDM amino acid mixture, $100 \mathrm{nM}$ of phytosulfokine and $25 \mu \mathrm{M}$ of NAA were added to the cooled medium.

Maturation induction was carried out in two different maturation mediums. The first, was DCR medium supplemented with $68 \mathrm{~g} \mathrm{~L}^{-1}$ sucrose, $1 \mathrm{~g} \mathrm{~L}^{-1}$ casein hydrolysate, $80 \mu \mathrm{M}$ abscisic acid (ABA), 
the EDM amino acid mixture, $0.5 \mathrm{~g} \mathrm{~L}^{-1}$ glutamine and $10 \mathrm{~g} \mathrm{~L}^{-1}$ gellan gum (Gelrite ${ }^{\circledR}$; Duchefa Biochemie, Amsterdam, Netherlands). The second, was DCR medium supplemented with $68 \mathrm{~g} \mathrm{~L}^{-1}$ sucrose, $1 \mathrm{~g} \mathrm{~L}^{-1}$ casein hydrolysate, $120 \mu \mathrm{M}$ ABA, the EDM amino acid mixture, $0.5 \mathrm{~g} \mathrm{~L}^{-1}$ glutamine and $12 \mathrm{~g} \mathrm{~L}^{-1}$ gellan gum (Gelrite ${ }^{\circledR}$; Duchefa Biochemie, Amsterdam, Netherlands). Eight Petri dishes per sample, containing $60 \mathrm{mg}$ of tissue each, were cultured in the dark for 18 weeks.

\subsubsection{Reinvigorated axillary shoots}

Twelve reinvigorated axillary shoots $(2.0-3.0 \mathrm{~cm})$ obtained through organogenesis (Figure 3a) from genotypes 17-3 and 17-4 were selected to SE induction. Needles were cut before culture (Figure $3 \mathrm{~b})$, without damage at the apical meristem, and seven to nine transversal shoot slices $(0.2-0.5 \mathrm{~cm})$ per explant were cultured on 3 different induction media (Figure 3c): IM1, IM2 and IM3.

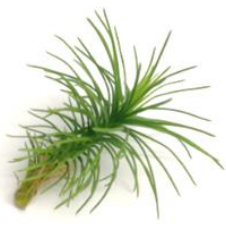

(a)

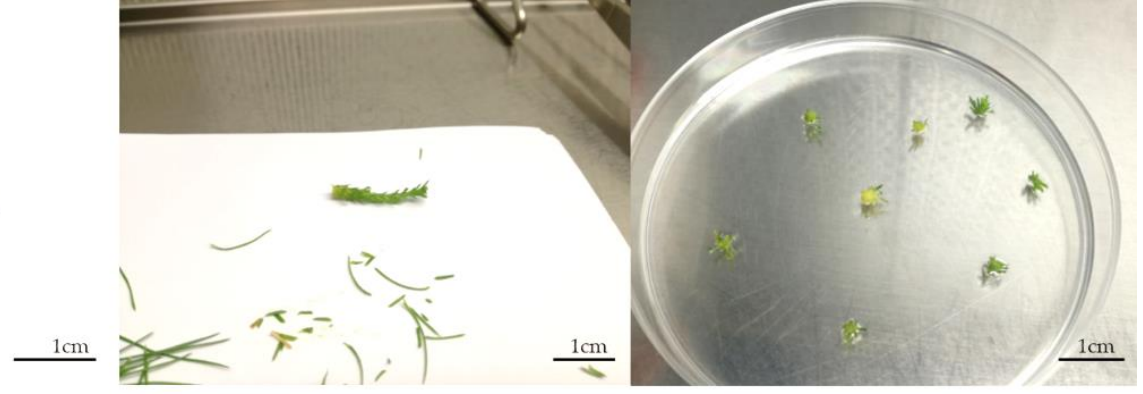

(b)

(c)

Figure 3. Induction of reinvigorated axillary shoots obtained through organogenesis in different SE induction media: (a) Reinvigorated axillary shoot through organogenesis; (b) Cutting of needles before culture of shoot slices; (c) Disposition of different shoot slices at induction medium.

IM1 medium was DCR supplemented with $30 \mathrm{~g} \mathrm{~L}^{-1}$ sucrose and $3.5 \mathrm{~g} \mathrm{~L}^{-1}$ gellan gum (Gelrite ${ }^{\circledast}$; Duchefa Biochemie, Amsterdam, Netherlands), with a combination of $2.7 \mu \mathrm{M}$ kinetin and $9.0 \mu \mathrm{M} 2,4-$ D, pH 5.7. After autoclaving, a filter-sterilized solution containing EDM amino acid mixture was added to the cooled medium. IM2 was DCR medium supplemented with $32 \mathrm{~g} \mathrm{~L}^{-1}$ maltose, $9 \mu \mathrm{M}$ of BA, $20 \mu \mathrm{M}$ of 2,4-D and $1.5 \mathrm{~g} \mathrm{~L}^{-1}$ gellan gum (Gelrite ${ }^{\circledR ;}$ Duchefa Biochemie, Amsterdam, Netherlands), $\mathrm{pH}$ 5.7. After autoclaving, a filter-sterilized solution containing EDM amino acid mixture, $50 \mathrm{nM}$ of phytosulfokine and $25 \mu \mathrm{M}$ of NAA were added to the cooled medium. IM3 had the same composition as IM2 with a concentration of $200 \mathrm{nM}$ of phytosulfokine.

Two to six Petri dishes per induction medium were cultured and maintained, at dark, at $23^{\circ} \mathrm{C}$. Calli were subcultured to the same induction medium, two times, after 5 and 10 weeks from the beginning of induction.

\section{Results}

\subsection{Organogenic process}

Contamination rates obtained in the first sample collection of 2017 were $48.2 \%$ for protocol (A), $49.1 \%$ for (B) and $89.0 \%$ for (C). Protocol (A) was selected for the rest of the experiment, and $43.9 \%$ of total contamination was obtained during this experiment.

Reinvigorated shoots from both BA treatments $(22$ and $44 \mu \mathrm{M})$ and from adult zygotic trees and juvenile somatic trees were obtained. Higher numbers of EFS (\%) and NS/E were obtained in explants cultured at induction medium supplemented with $44 \mu \mathrm{M}$ BA. No statistically significant differences were found for EFS (\%) (Table 1). However, significant differences were obtained for the NS/E, since treatment at $44 \mu \mathrm{M}$ BA (5.73) led to more than double NS/E than treatment with $22 \mu \mathrm{M}$ BA (2.39) (Table 1, 2).

Table 1. T-test analysis of variance for EFS (explants forming shoots) (\%) and NS/E (number of shoots formed per explant) of Pinus halepensis apical shoot buds induced under two different concentrations 
of BA (22 and $44 \mu \mathrm{M} \mathrm{L}^{-1}$ ) and Kruskal-Wallis analyses for ex vitro rooting of five different genotypes (H8, H32, 17-3, P1, P8).

\begin{tabular}{cccc}
\hline $\begin{array}{c}\text { Source } \\
\boldsymbol{t} \text {-test }\end{array}$ & $\mathbf{d} \boldsymbol{f}$ & $\boldsymbol{t}$ & $\boldsymbol{P}$ value \\
\hline EFS & 38 & 0.8214 & n.s. \\
NS/E & 36 & 2.499 & 0.0172 \\
Kruskal-Wallis & $\mathbf{d} \boldsymbol{P}$ & $\mathbf{X}^{\mathbf{2}}$ test & $\boldsymbol{P}$ value \\
\hline Ex-vitro Rooting & 4 & 2.613 & n.s. \\
\hline & ${ }^{1}$ not statistically different.
\end{tabular}

Table 2. Values for EFS (\%) (explants forming shoots) and NS/E (number of shoots formed per explant) for Pinus halepensis apical shoot buds induced under two different concentrations of BA (22 and $44 \mu \mathrm{M})$.

\begin{tabular}{ccc}
\hline Treatment & EFS (\%) & NS/E \\
\hline $22 \mu \mathrm{M} \mathrm{L}^{-1} \mathrm{BA}$ & $30.15 \pm 5.56^{\mathrm{a}}$ & $2.39 \pm 0.52^{\mathrm{b}}$ \\
$44 \mu \mathrm{M} \mathrm{L}^{-1} \mathrm{BA}$ & $37.01 \pm 6.22^{\mathrm{a}}$ & $5.73 \pm 1.2^{\mathrm{a}}$ \\
\hline
\end{tabular}

Data are presented as mean values \pm SE. Significant differences at $p<0.05$ within a column are indicated by different letters

No data could be obtained from families 17.5, H29, H5 and P7 since $100 \%$ of the cultured explants were contaminated. The rates of contamination were noticed to be related to the condition of the initial explant but, also, to its development stage. When explants consisted of apical shoot buds at an advanced developmental stage, with open scales (Figure 1b), higher contamination rates were observed, as in the third collection of P5 and P6 when a $100 \%$ rate of contamination was recorded.

None of the shoots cultured on root-induction medium developed roots in vitro. Nevertheless, acclimatized ex vitro true to type plants from five different genotypes (H8, H32, 17.3, P1 and P8) were successfully obtained, since ex vitro roots developed. Regarding the acclimatization percentages, no statistically differences were found between different genotypes (Table 1). However, the mean percentage was $65 \%$ for genotype $\mathrm{H} 8$ while the other four genotypes mean percentages were between 20 to $25 \%$ (Figure 4 ).

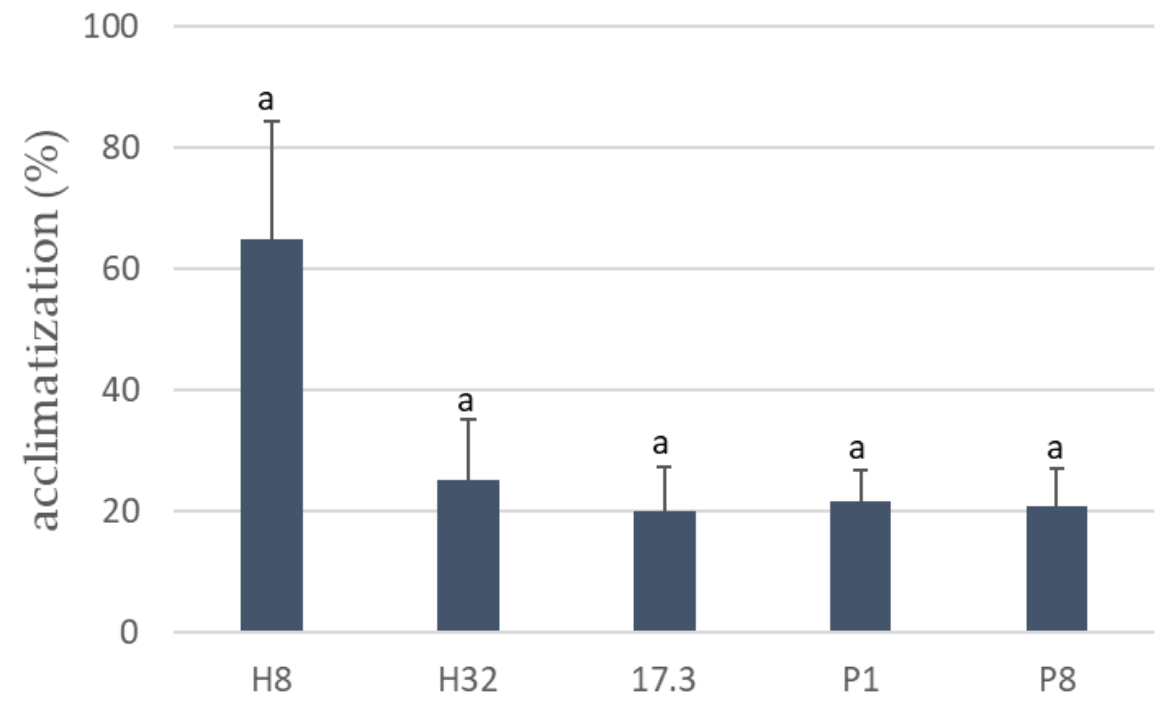

Figure 4. Acclimatization percentages of five different genotypes (H8, H32, 17.3, P1 and P8).

\subsection{Towards somatic embryogenesis induction}


A total of $61 \%$ of contamination was obtained when apical shoot buds were submitted to SE induction. $94.2 \%$ of the non-contaminated explants were induced and able to produce embryogenic like tissue. Despite the fact that all calli induced were non-embryogenic, and no somatic embryos were produced during this experiment, they showed good proliferation capacity either when subcultures were made directly on proliferation medium or on filter paper. Likewise, proliferation of calli was persistent on different proliferation media (50 and $100 \mathrm{nM}$ phytosulfokine) and temperatures (23 and $28^{\circ} \mathrm{C}$ ). Nonetheless, variations at morphologic characteristics such has variations in colour, texture and consistence were observed at different conditions.

Induction response of apical shoot buds from juvenile somatic trees (represented in Figure 1a), is displayed in Figure 3. Bud slices were cultured on their growth position on the induction medium (Figure 5a) and approximately a week after culture, white-green soft tissue begun to appear, first at the wounded areas and then throughout all the explant (Figure 5b, c). Explants subcultured directly on proliferation media had a watery texture at first (Figure $5 \mathrm{~d}$ ), and then, with subcultures, started to stiffen and to acquire a yellowish colour (Figure 5e). When embryogenic-like tissue was detached from the explant and subcultured on filter paper, a more compact tissue developed. Both clusters with brown, hard to disaggregate tissue and clusters with whiter, soften callus could be observed on proliferation media with 50 and $100 \mathrm{nM}$ phytosulfokine (Figure $5 \mathrm{f}, \mathrm{g}$ ). Some callus presented a more similar texture and colour to embryogenic ones (Figure $5 \mathrm{~h}$ ). However, acetocarmine staining $(2 \% \mathrm{w} / \mathrm{v})$ (Figure 5i), and the fact that no somatic embryos were obtained, confirmed that this callus remained non-embryogenic.

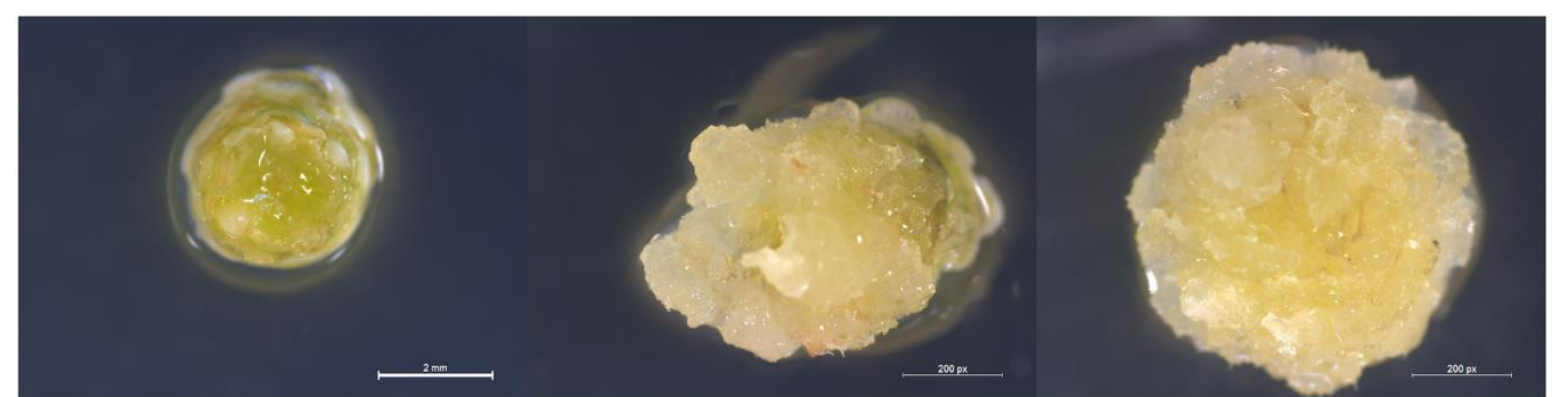

(a)

(b)

(c)

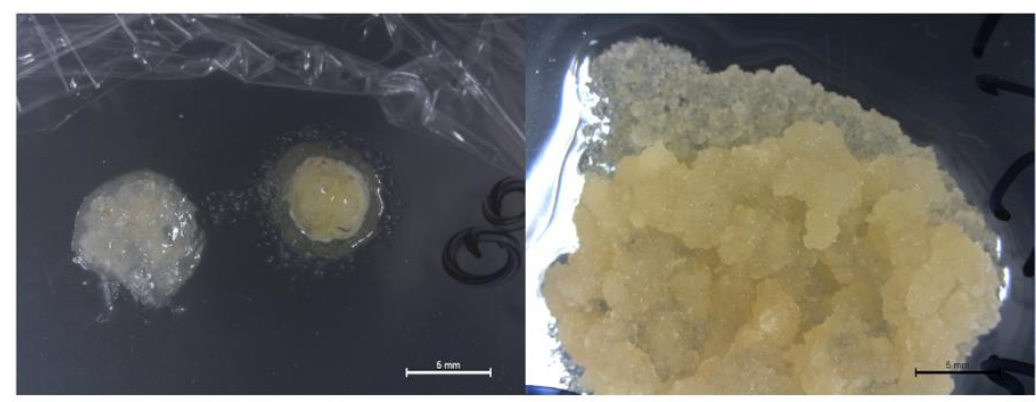

(d)

(g)

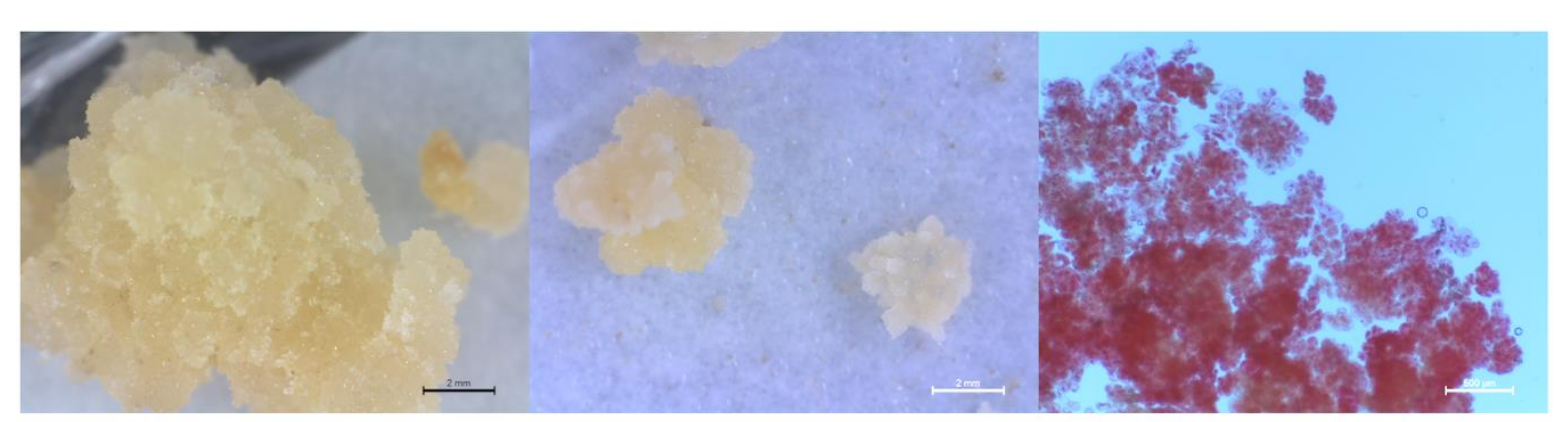

(e)

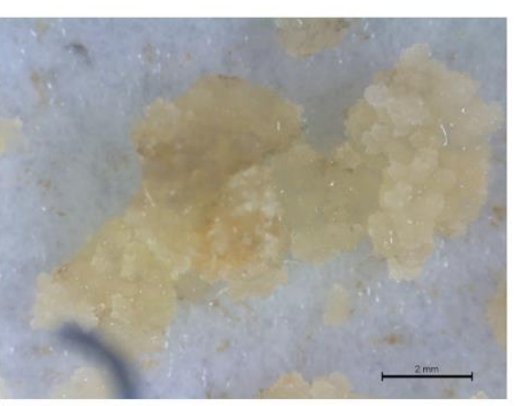

(f) 
Figure 5. Induction response of shoot buds from juvenile somatic trees: (a) Bud slice in SE induction medium; (b) Tissue development in the wounded areas of the explant; (c) Tissue development throughout all the explant; (d) Non-embryogenic callus subcultured directly on proliferation medium; (e) Later proliferation of non-embryogenic callus directly subcultured; (f) Filtered cultured tissue on proliferation medium with $50 \mathrm{nM}$ phytosulfokine; (g) Filtered cultured tissue on proliferation medium with $100 \mathrm{nM}$ phytosulfokine; (h) example of non-embryogenic callus (bottom right) with similarities with embryogenic one (i) cells collected from the lower cluster represented before and stained with acetocarmine $(2 \% \mathrm{w} / \mathrm{v})$.

Induction response of apical shoot buds from zygotic mature trees (represented in Figure 1b), is displayed in Figure 6. Different from the above-mentioned explants, these bud slices firstly developed a white-green soft tissue at the upper wounded area and then, this tissue growing only at this location of the explant, started to stiffen and to acquire a yellowish colour before the first subculture (Figure 6a, b). When comparing the differences obtained in calli proliferated at $23^{\circ} \mathrm{C}$ (Figure 6c) and $28{ }^{\circ} \mathrm{C}$ (Figure $6 \mathrm{~d})$, calli presented a darker colour and stiffer morphology when cultured at the last.

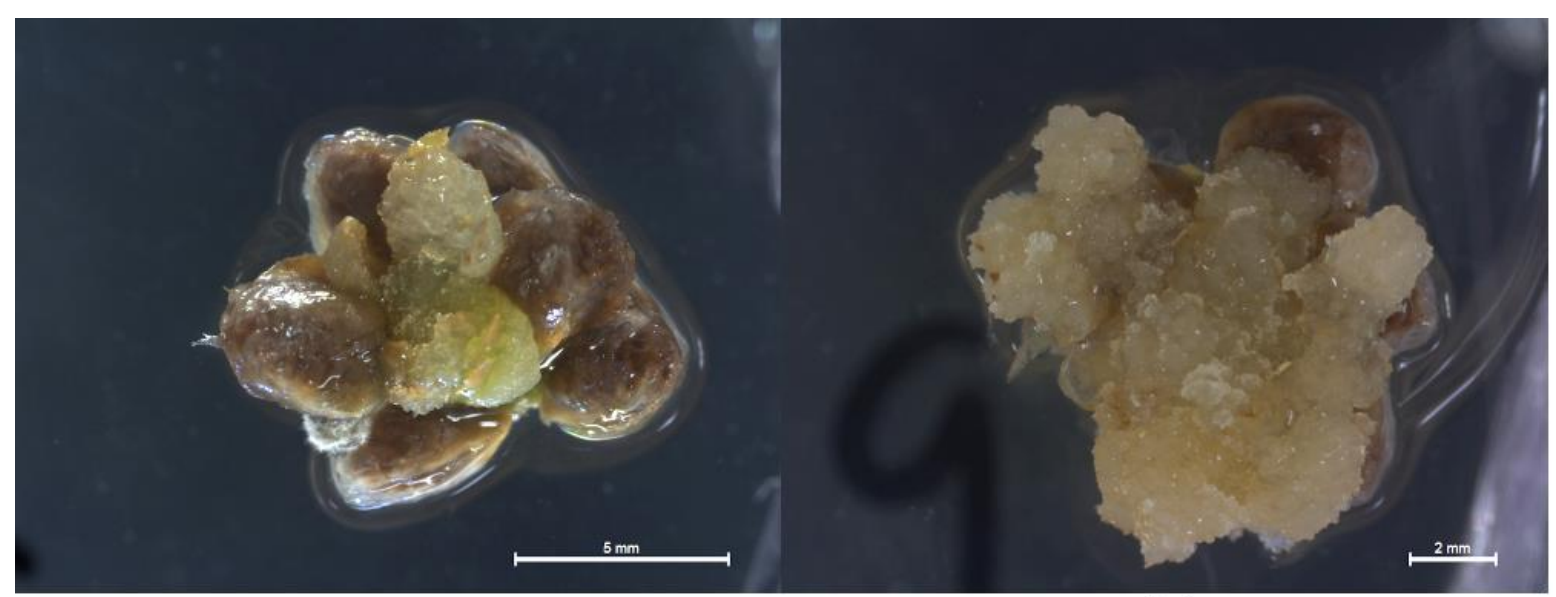

(a)

(b)

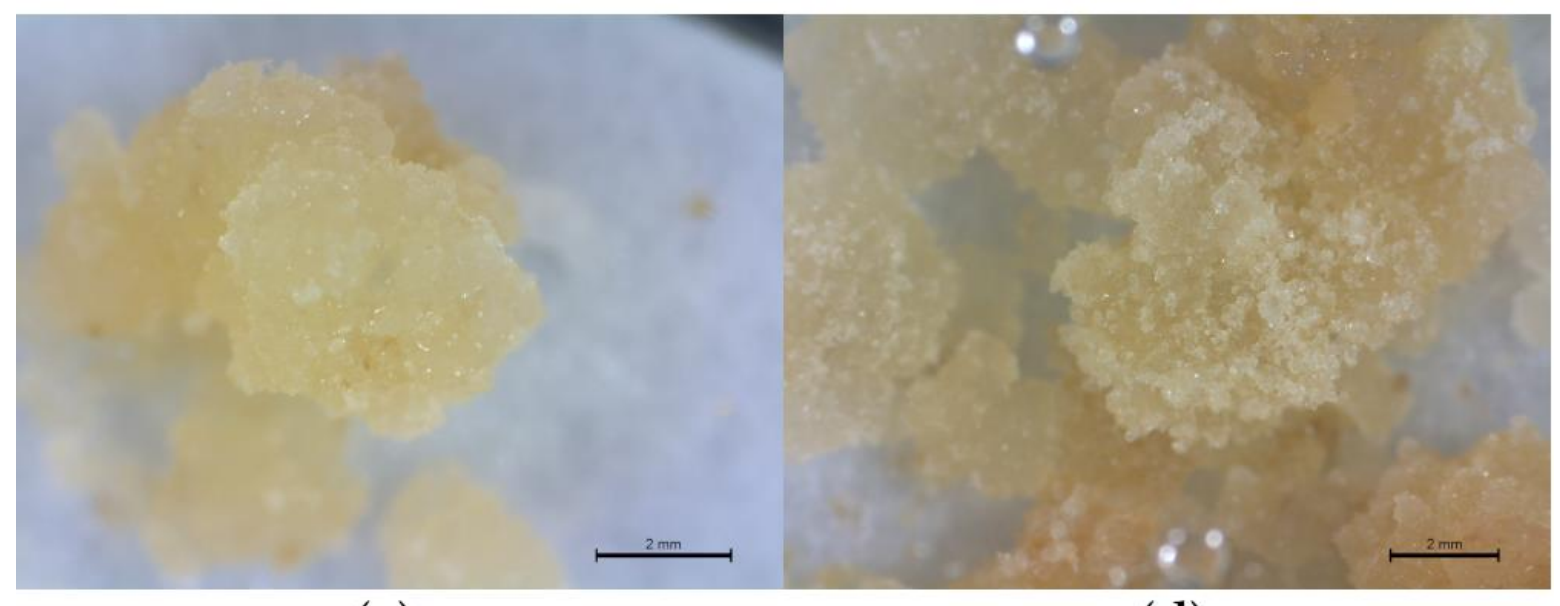

(c)

(d)

Figure 6. Induction response of shoot buds from adult trees: (a) Bud slice in SE induction medium with tissue development in the upper wounded area of the explant; (b) Progress of the tissue development in the upper area of the explant with no tissue development throughout the all explant; (c) Filtered cultured tissue proliferating at $23^{\circ} \mathrm{C}$; (d) Filtered cultured tissue proliferating at $28{ }^{\circ} \mathrm{C}$.

Finally, all shoot slices from reinvigorated axillary shoots cultured on SE induction media were able to produce non-embryogenic callus. Tissue obtained in IM1 (Figure 7a) was brown, stiffer and harder to disaggregate than the ones obtained in IM2 (Figure 7b) and IM3 (Figure 7c). Also, calli 
produced in IM3 presented lighter colour and softer and easiest to the disaggregate morphology. Calli induced in IM2 presented an intermediate aspect.

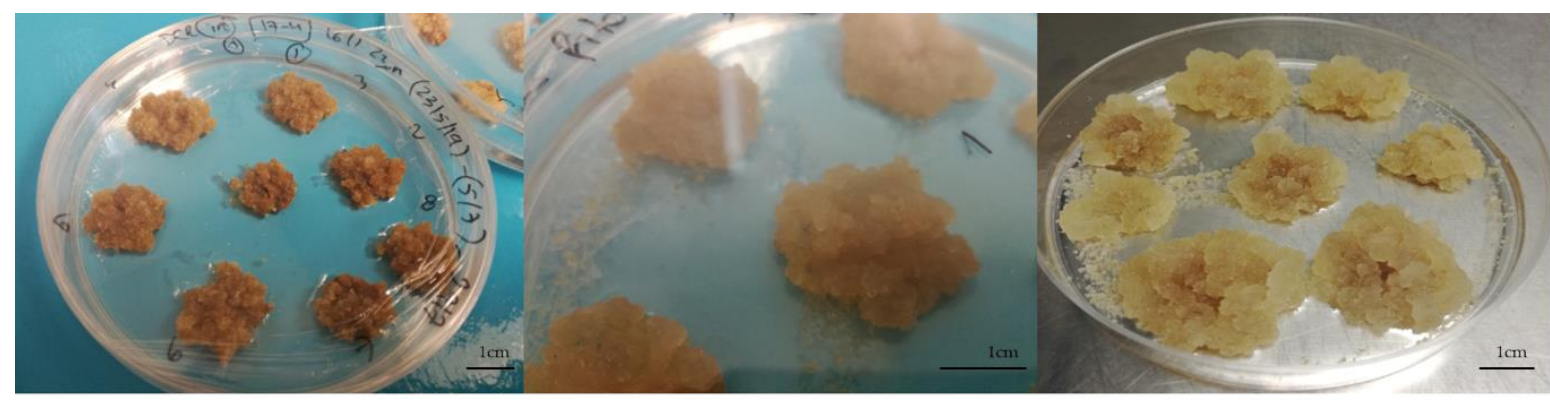

(a)

(b)

(c)

Figure 7. Response of reinvigorated axillary shoots obtained through organogenesis in different SE induction media: (a) Non-embryogenic calli formed in IM1; (b) Non-embryogenic calli formed in IM2; (c) Non-embryogenic calli formed in IM3.

\section{Discussion}

\subsection{Organogenic process}

The common criteria to identify reinvigoration or rejuvenation of explants are based on morphology, morphogenic capacity and the ability to produce cones or flowers [30]. However, uncertainties remain over whether true rejuvenation can be reached by artificial methods, or whether these methods merely provide reinvigoration through continuous in vitro subculture of shoots. In the present study, we were able to obtain reinvigorated axillary shoots, through organogenesis, from the two BA treatments tested (22 and $44 \mu \mathrm{M})$, using apical shoot buds as explants, and acclimatized plants. Our reinvigorated axillary shoots showed changes, specially, in the appearance of the needles, which were thinner with a lighter green color when compared to the mature ones of the respective donor trees.

In this study, we used three different sterilization protocols that included ethanol, commercial bleach and silver nanoparticles, and the higher decontamination was obtained with bleach. An effective elimination of contamination could contribute to a better establishment of the shoot buds. This must be achieved with the least possible damage, since a minor injury caused during sterilization can block future growth and development of the explants. As reviewed in [31], ethanol and sodium hypochlorite are two of the most common chemicals used to decontaminate woody species, however, silver nanoparticles are quite effective in controlling physiochemical changes, preventing bacterial infections and actively block ethylene through the release of silver ions, which could improve induction of explants. Despite the fact that in our case the sterilization with nanoparticles was not efficient, changes in time or concentrations could lead to better results and explant quality [32,33].

The evaluation organogenic response was made by taking into account the percentage of explants forming shoots [EFS (\%)] and the number of shoots formed per explant (NS/E). The results showed that no statistically significant differences between treatments were obtained for EFS (\%). When mature embryos were used as explants in this species [24], a cytokinin alone, specially BA at the higher concentration tested $(10 \mu \mathrm{M})$, also proved satisfactory for bud induction. Likewise, BA, alone or in combination with other cytokinins, has been the most used growth regulator in organogenesis and the concentration of this growth regulator plays an important role in the explant response [17]. Several micropropagation protocols for induction of axillary shoots in Pinus species supplement the culture media with different concentrations of BA, ranging from 1 to $50 \mu \mathrm{M}$ $[19,20,24,34,35]$.

When the induction medium was supplemented with $44 \mu \mathrm{M}$ BA, the NS/E obtained in explants was more than double than the ones induced at $22 \mu \mathrm{M}$ BA. These results are in agreement with the ones obtained in Pinus pinea [36], where higher concentrations of BA $(44.4 \mu \mathrm{M})$, when compared to 
4.4 and $10 \mu \mathrm{M}$, led to significant higher number of buds formed per explant during the first 16 days of culture; in contrast, after 35 days in culture, there were no differences between the three concentrations tested. In Pinus roxburghii [34] and P. pinaster [17] higher concentrations of BA promoted lower organogenic capacity or lower elongation rates. In P. elliottii [37], it was also showed that high levels of cytokinins may interfere with the normal development of axillary shoots and, despite the promotion of bud induction, it may compromise cell elongation and thus shoot elongation. It appears that the toxic environment created by the excess of BA in those species did not happen in our case and that the use of $\mathrm{AC}$ in our elongation medium proved efficient to detoxify the culture medium at both concentrations tested (22 and $44 \mu \mathrm{M} \mathrm{BA})$. As reviewed in [38], some of the positive effects of the use of $\mathrm{AC}$ in micropropagation can be attributed to the removal of inhibitory substances from the media itself and of toxic plant metabolites released from the tissue in culture.

It is widely recognized that different genotypes and genetic backgrounds may lead to differences in terms of in vitro performance and cloning capacity in different conifer species [12,39]. Despite that fact, the mean results obtained for different genotypes presented, in general, higher EFS (\%) and NS/E at explants cultured at $44 \mu \mathrm{MBA}$ and no differences were obtained regarding ex vitro rooting between different genotypes.

The axillary shoots cultured on root-induction medium did not developed roots in vitro, however, during acclimatization, ex vitro roots developed. Contrary, both pulses of IBA for five days in solid medium and liquid pulses for four hours previously proved efficient to the development of in vitro roots in this species [24]. This can be due to the fact that, in that study, juvenile explants (mature zygotic embryos) were used. Adventitious rooting is an essential but sometimes rate-limiting step and plant growth regulators, mostly auxins, are crucial for root induction [13]. For many years, IBA has been applied to different plant species to induce adventitious roots [40]. Our plants were able to produce ex-vitro roots and acclimatize successfully, but further testing of different hormones, alone or in different combinations, and for different induction times could be tested in order to improve this regeneration protocol for Aleppo pine. The use of NAA, combined with IBA or alone, has proved successful to induce root meristem differentiation in Pinus species [41,42].

\subsection{Towards somatic embryogenesis induction}

In this work, we used various explants for SE induction: apical shoot buds from both somatic and zygotic trees, as well as reinvigorated axillary shoots developed during organogenesis. Woody species suffer a "phase change" or ontogenetic aging during their development, defined as a shift from the juvenile state to the adult state, which is usually characterized by a decrease in growth and the start of flowering [39,43]. Once this shift occurs, there is a significant loss of organogenic and embryogenic capacity. Also, initial explants had been considered the most important factor for mature SE accomplishment and it has been suggested that culture-derived material could be more responsive in tissue culture $[39,44]$.

In addition to explants, plant growth regulators, culture conditions and media composition also have a great influence in the embryogenic response [45]. Various induction media with different combinations of auxins (2,4-D and NAA) along with lower concentrations of cytokinins (BA and kinetin) were tested for induction of the explants. As mentioned before, the ratio between auxin and cytokinins can be determinant to explants developmental fate in vitro [16]. Cytokinins, or a higher ratio of cytokinin to auxin, is usually required for the induction of shoot organogenesis, while higher ratios of auxin to cytokinins typically favors SE [11]. Our basal media were based in one used in Pinus contorta [27], since they were able to induce embryogenic-like tissue from shoot buds of mature trees; and the one used in SE induction from immature megagametophytes of $P$. halepensis, previously established in our laboratory $[25,46]$.

All embryogenic-like tissue obtained initially produced non-embryogenic calli in the proliferation stage and no somatic embryos were produced. The primary objective of induction phase is for the explant's somatic cells to acquire embryogenic competence and, for that, reprogramming of gene expression followed by polarized growth of the cells is required [45]. The success of this step is essential for the entire process [47]. Nonetheless, the non-embryogenic tissue obtained presented proliferation capacity. Likewise, in Pinus contorta [27], they were able to develop calli with 
proliferation capacity and different morphologies, some of them with an embryogenic-like structure, that at the end were not able to produce somatic embryos. Non-embryogenic callus, in other Pinus species, has also been described as white yellowish friable tissue, containing spherical cells with prominent nuclei and without evidence of polarity, that grows darker and necrotic with time $[48,49]$. Also, a study developed in our laboratory [50], tested different explants at different development stages with similar induction mediums. In that study, similar characteristics were found at nonembryogenic calli, and despite the efforts to convert them to embryogenic tissue with treatments with auxins, mannitol, sucrose and variations of $\mathrm{pH}$, they did not gain embryogenic characteristics.

Finally, we tested the influence of phytosulfokine in induction medium, a small sulfated peptide involved in the initial step of cellular dedifferentiation, proliferation and re-differentiation [51]. It did not lead to the ultimate formation of somatic embryos, however, it helped maintain the induced calli proliferating with a lighter color and softer and easiest to the disaggregate morphology. In Daucus carota [52], Cryptomeria japonica [51] and Pinus elliottii [53] phytosulfokine also significantly increased cell division and proliferation, as well as their embryogenic capacity and the number of somatic embryos developed.

\section{Conclusions}

In this study, the regeneration of $P$. halepensis through organogenesis using apical shoot buds as explants was successfully achieved. Reinvigorated shoots from both juvenile somatic trees and adult trees were obtained. Also, true to type plants from five different genotypes (H8, H32, 17.3, P1 and P8) were successfully obtained and acclimatized. This is the first report of in vitro regeneration from mature trees in this species.

Despite our efforts to induce somatic embryogenesis from mature trees and eliminate the narrow competence window that exist in this species we were not able to produce somatic embryos. Nonetheless, we were able to produce proliferating embryogenic like tissue. Further studies on different explants, medium composition and environmental factors, as well as shock treatments that could have an influence in obtaining embryogenic calli able to be maturated will lead to the muchdesired goal of cloning conifer mature trees via SE.

Author Contributions: conceptualization, P.M. and J.C.; methodology, P.M., J.C., I.A.M., A.P. ${ }^{2}$, N.B.; formal analysis, C.P.; investigation, C.P., J.T., A.P. ${ }^{1}$; data curation, C.P.; writing-original draft preparation, C.P.; writing-review and editing, C.P., J.C., P.M. and I.A.M.; supervision, P.M., J.C.

Funding: This research was funded by MINECO (Spanish Government) project (AGL2016-76143-C4-3R), BIOALI-CYTED (P117RT0522), DECO (Basque government, Ayudas de formación a jóvenes investigadores y tecnólogos), Renature: Projecto ReNature (Centro-01-0145-FEDER-000007) - Valorização dos Recursos Naturais Endógenos da Região Centro, and Portuguese Foundation for Science and Technology (FCT) (SFRH/BD/123702/2016), Fundo Social Europeu (FSE), and Programa Operacional Regional do CENTRO Centro 2020 (UE).

Acknowledgments: This work is carried out at the R\&D Unit Center for Functional Ecology - Science for People and the Planet (CFE), with reference UIDB/04004/2020, financed by FCT/MCTES through national funds (PIDDAC). MULTIFOREVER (Project MULTIFOREVER is supported under the umbrella of ERA-NET cofund Forest Value by ANR (FR), FNR (DE), MINCyT (AR), MINECO-AEI (ES), MMM (FI) and VINNOVA (SE). Forest value has received funding from the European Union's Horizon 2020 research and innovation programmed under agreement № 773324 .

Conflicts of Interest: The authors declare no conflict of interest. The funders had no role in the design of the study; in the collection, analyses, or interpretation of data; in the writing of the manuscript, or in the decision to publish the results.

\section{References}

1. Boisvenue, C.; Running, S.W. Impacts of climate change on natural forest productivity - evidence since the middle of the 20th century. Glob. Chang. Biol. 2006, 12, 862-882. 
2. von Arnold, S.; Clapham, D.; Abrahamsson, M. Embryology in conifers. In Advances in Botanical Research, $1^{\text {st }}$ ed.; Cánovas F.N. Ed; Elsevier: Massachusetts, USA, 2019; Volume 89, pp. 157-184.

3. Klimaszewska, K.; Trontin, J.-F.; Becwar, M.R.; Devillard, C.; Park, Y.-S.; Lelu-Walter, M.-A. Recent progress in somatic embryogenesis of four Pinus spp. Tree For. Sci. Biotechnol. 2007, 1, 11-25.

4. Ne'eman, G.; Goubitz, S.; Nathan, R. Reproductive traits of Pinus halepensis in the light of fire - A critical review. Plant Ecol. 2004, 171, 69-79.

5. Klein, T.; Cohen, S.; Yakir, D. Hydraulic adjustments underlying drought resistance of Pinus halepensis. Tree Physiol. 2011, 31, 637-648.

6. Vennetier, M.; Ripert, C.; Rathgeber, C.; Bellot, J.; Maestre, F.T.; Chirino, E.; Hernández, N.; De Urbina, J.O.; Botella, L.; Santamaría, O.; et al. Afforestation with Pinus halepensis reduces native shrub performance in a Mediterranean semiarid area. Fungal Divers. 2010, 41, 9-18.

7. Botella, L.; Santamaría, O.; Diez, J.J. Fungi associated with the decline of Pinus halepensis in Spain. Fungal Divers. 2010, 40, 1-11.

8. Sugiyama, M. Historical review of research on plant cell dedifferentiation. J. Plant Res. 2015, 128, 349359.

9. Vasil, I.K. A history of plant biotechnology: From the cell theory of Schleiden and Schwann to biotech crops. Plant Cell Rep. 2008, 27, 1423-1440.

10. Ramage, C.M.; Williams, R.R. Mineral nutrition and plant morphogenesis. Vitr. Cell. Dev. Biol. - Plant 2002, 38, 116-124.

11. Zhang, S.; Lemaux, P.G. Molecular analysis of in vitro shoot organogenesis. CRC. Crit. Rev. Plant Sci. 2004, 23, 325-335.

12. Bonga, J.M.; Klimaszewska, K.K.; von Aderkas, P. Recalcitrance in clonal propagation, in particular of conifers. Plant Cell. Tissue Organ Cult. 2010, 100, 241-254.

13. Díaz-Sala, C. Direct reprogramming of adult somatic cells toward adventitious root formation in forest tree species: The effect of the juvenile-adult transition. Front. Plant Sci. 2014, 5, 1-8.

14. Bonga, J.M. Can explant choice help resolve recalcitrance problems in in vitro propagation, a problem still acute especially for adult conifers? Trees - Struct. Funct. 2017, 31, 781-789.

15. de Almeida, M.; de Almeida, C.V.; Graner, E.M.; Brondani, G.E.; de Abreu-Tarazi, M.F. Pre-procambial cells are niches for pluripotent and totipotent stem-like cells for organogenesis and somatic embryogenesis in the peach palm: A histological study. Plant Cell Rep. 2012, 31, 1495-1515.

16. Skoog, F.; Miller, C.O. Chemical regulation of growth and organ formation in plant tissues cultured. Symp. Soc. Exp. Biol. 1957, 11, 118-131.

17. De Diego, N.; Montalbán, I.A.; Fernandez De Larrinoa, E.; Moncaleán, P. In vitro regeneration of Pinus pinaster adult trees. Can. J. For. Res. 2008, 38, 2607-2615.

18. De Diego, N.; Montalbán, I.A.; Moncaleán, P. In vitro regeneration of adult Pinus sylvestris L. trees. South African J. Bot. 2010, 76, 158-162.

19. Montalbán, I.A.; De Diego, N.; Moncaleán, P. Testing novel cytokinins for improved in vitro adventitious shoots formation and subsequent ex vitro performance in Pinus radiata. Forestry 2011, 84, 363-373.

20. Cortizo, M.; de Diego, N.; Moncaleán, P.; Ordás, R.J. Micropropagation of adult Stone Pine (Pinus pinea L.). Trees - Struct. Funct. 2009, 23, 835-842.

21. Becwar, M.R.; Nagmani, R.; Wann, S.R. Initiation of embryogenic cultures and somatic embryo development in loblolly pine ( Pinus taeda ) . Can. J. For. Res. 1990, 20, 810-817.

22. Carneros, E.; Celestino, C.; Klimaszewska, K.; Park, Y.S.; Toribio, M.; Bonga, J.M. Plant regeneration in Stone pine (Pinus pinea L.) by somatic embryogenesis. Plant Cell. Tissue Organ Cult. 2009, 98, 165-178. 
23. Castander-Olarieta, A.; Moncaleán, P.; Montalbán, I.A. Pinus canariensis plant regeneration through somatic embryogenesis. For. Syst. 2020, 29, 61-66.

24. Lambardi, M.; Sharma, K.K.; Thorpe, T.A. Optimization of in vitro bud induction and plantlet formation from mature embryos of Aleppo pine (Pinus halepensis Mill.). Vitr. Cell. Dev. Biol. - Plant 1993, 29, 189199.

25. Montalbán, I.A.; Setién-Olarra, A.; Hargreaves, C.L.; Moncaleán, P. Somatic embryogenesis in Pinus halepensis Mill.: an important ecological species from the Mediterranean forest. Trees 2013, 27, 1339-1351.

26. Gupta, P.K.; Durzan, D.J. Plantlet regeneration via somatic embryogenesis from subcultured callus of mature embryos of Picea abies (Norway spruce). Vitr. Cell. Dev. Biol. 1986, 22, 685-688.

27. Park, S.Y.; Klimaszewska, K.; Park, J.Y.; Mansfield, S.D. Lodgepole pine: The first evidence of seed-based somatic embryogenesis and the expression of embryogenesis marker genes in shoot bud cultures of adult trees. Tree Physiol. 2010, 30, 1469-1478.

28. Walter, C.; Find, J.I.; Grace, L.J. Somatic embryogenesis and genetic transformation in Pinus radiata. In Protocol for Somatic Embryogenesis in Woody Plants; Jain, S.M., Gupta, P.K., Eds.; Springer: Dordrecht, 2005; pp. 11-24.

29. Montalbán, I.A.; De Diego, N.; Moncaleán, P. Bottlenecks in Pinus radiata somatic embryogenesis: improving maturation and germination. Trees 2010, 24, 1061-1071.

30. Wendling, I.; Trueman, S.J.; Xavier, A. Maturation and related aspects in clonal forestry-part II: Reinvigoration, rejuvenation and juvenility maintenance. New For. 2014, 45, 473-486.

31. Sarmast, M.K. In vitro propagation of conifers using mature shoots. J. For. Res. 2018, 29, 565-574.

32. Kim, D.H.; Gopal, J.; Sivanesan, I. Nanomaterials in plant tissue culture: The disclosed and undisclosed. RSC Adv. 2017, 7, 36492-36505.

33. Bello-Bello, J.J.; Chavez-Santoscoy, R.A.; Lecona-Guzmán, C.A.; Bogdanchikova, N.; Salinas-Ruíz, J.; Gómez-Merino, F.C.; Pestryakov, A. Hormetic response by silver nanoparticles on in vitro multiplication of sugarcane (Saccharum spp. Cv. Mex 69-290) using a temporary immersion system. Dose-Response 2017, 15, 1-9.

34. Kalia, R.K.; Arya, S.; Kalia, S.; Arya, I.D. Plantlet regeneration from fascicular buds of seedling shoot apices of Pinus roxburghii Sarg. Biol. Plant. 2007, 51, 653-659.

35. Stojičić, D.; Budimir, S.; Ćulafić, L. Micropropagation of Pinus heldreichii. Plant Cell. Tissue Organ Cult. 1999, 59, 147-150.

36. Moncaleán, P.; Alonso, P.; Centeno, M.L.; Cortizo, M.; Rodríguez, A.; Fernández, B.; Ordás, R.J. Organogenic responses of Pinus pinea cotyledons to hormonal treatments: BA metabolism and cytokinin content. Tree Physiol. 2005, 25, 1-9.

37. Nunes, S.; Sousa, D.; Pereira, V.T.; Correia, S.; Marum, L.; Santos, C.; Dias, M.C. Efficient protocol for in vitro mass micropropagation of slash pine. Vitr. Cell. Dev. Biol. - Plant 2018, 54, 175-183.

38. Pan, M.J.; Van Staden, J. The use of charcoal in in vitro culture - A review. Plant Growth Regul. 1998, 26, 155-163.

39. Von Aderkas, P.; Bonga, J.M. Influencing micropropagation and somatic embryogenesis in mature trees by manipulation of phase change, stress and culture environment. Tree Physiol. 2000, 20, 921-928.

40. Ragonezi, C.; Klimaszewska, K.; Castro, M.R.; Lima, M.; de Oliveira, P.; Zavattieri, M.A. Adventitious rooting of conifers: Influence of physical and chemical factors. Trees - Struct. Funct. 2010, 24, 975-992.

41. Álvarez, J.M.; Majada, J.; Ordás, R.J. An improved micropropagation protocol for maritime pine (Pinus pinaster Ait.) isolated cotyledons. Forestry 2009, 82, 175-184.

42. Montalbán, I.A.; Novák, O.; Rolčik, J.; Strnad, M.; Moncaleán, P. Endogenous cytokinin and auxin 
profiles during in vitro organogenesis from vegetative buds of Pinus radiata adult trees. Physiol. Plant. 2013, 148, 214-231.

43. Díaz-Sala, C. Molecular dissection of the regenerative capacity of forest tree species: Special focus on conifers. Front. Plant Sci. 2019, 9, 1-10.

44. Klimaszewska, K.; Overton, C.; Stewart, D.; Rutledge, R.G. Initiation of somatic embryos and regeneration of plants from primordial shoots of 10-year-old somatic white spruce and expression profiles of 11 genes followed during the tissue culture process. Planta 2011, 233, 635-647.

45. Corredoira, E.; Merkle, S.A.; Martínez, M.T.; Toribio, M.; Canhoto, J.M.; Correia, S.I.; Ballester, A.; Vieitez, A.M. Non-zygotic embryogenesis in hardwood species. CRC. Crit. Rev. Plant Sci. 2019, 38, 2997.

46. Pereira, C.; Montalbán, I.A.; García-Mendiguren, O.; Goicoa, T.; Ugarte, M.D.; Correia, S.; Canhoto, J.M.; Moncaleán, P. Pinus halepensis somatic embryogenesis is affected by the physical and chemical conditions at the initial stages of the process. J. For. Res. 2016, 21, 143-150.

47. Stasolla, C.; Thorpe, T. Tissue culture: historical perspectives and applications. Appl. Plant Biotechnol. 2011, 15-305.

48. Salaj, T.; Klubicová, K.; Matusova, R.; Salaj, J. Somatic embryogenesis in selected conifer trees Pinus nigra Arn. and abies hybrids. Front. Plant Sci. 2019, 10, 1-13.

49. Klubicová, K.; Uvácková, L.; Danchenko, M.; Nemecek, P.; Skultéty, L.; Salaj, J.; Salaj, T. Insights into the early stage of Pinus nigra Arn. somatic embryogenesis using discovery proteomics. J. Proteomics 2017, 169, 99-111.

50. Tavares, J.J.D.M. In vitro morphogenesis assays in Pinus halepensis Mill. Masters Thesis, University of Coimbra, Portugal, 2019.

51. Igasaki, T.; Akashi, N.; Ujino-Ihara, T.; Matsubayashi, Y.; Sakagami, Y.; Shinohara, K. Phytosulfokine stimulates somatic embryogenesis in Cryptomeria japonica. Plant Cell Physiol. 2003, 44, 1412-1416.

52. Kobayashi, T.; Eun, C.H.; Hanai, H.; Matsubayashi, Y.; Sakagami, Y.; Kamada, H. Phytosulphokine- $\alpha$, a peptidyl plant growth factor, stimulates somatic embryogenesis in carrot. J. Exp. Bot. 1999, 50, 1123-1128.

53. Yang, F.; Xia, X.R.; Ke, X.; Ye, J.; Zhu, L. Somatic embryogenesis in slash pine (Pinus elliottii Engelm): improving initiation of embryogenic tissues and maturation of somatic embryos. Plant Cell. Tissue Organ Cult. 2020, 143, 159-171. 